\title{
Produtividade e desenvolvimento de cultivares de repolho em função de doses de boro
}

\author{
Katiane S Silva ${ }^{1}$; Evellyn da CM dos Santos ${ }^{2}$; Cleiton GS Benett ${ }^{2}$; Laís T Laranjeira ${ }^{2}$; Erich Eberhardt \\ Neto $^{3}$; Edilson Costa ${ }^{2}$ \\ 'UEG-UnU, Rod. GO 330 km 241, Anel Viário s/n, 75780-000 Ipameri-GO; kasantiago@ig.com.br; 2UEMS-UUA, C. Postal 25, 79200- \\ 000 Aquidauana-MS; cbenett@hotmail.com; mestrine@uems.br; evellyn_smell@hotmail.com; lalaranjeira@hotmail.com; 3UNESP- \\ FCA, C. Postal 237,18610-307, Botucatu-SP; erich.88@hotmail.com
}

\section{RESUMO}

A cultura do repolho é cultivada em áreas pequenas e necessita de muita mão de obra, sendo na maior parte conduzida pela agricultura familiar. Avaliou-se o efeito de doses de boro em diferentes cultivares de repolho na região oeste de Mato Grosso do Sul. O experimento foi conduzido na Universidade Estadual de Mato Grosso do Sul, Unidade Universitária de Aquidauana. O delineamento experimental utilizado foi de blocos casualizados no esquema fatorial 2 x 5 , sendo duas cultivares e cinco doses de boro, com quatro repetições. Foram avaliadas as características: teores de boro foliar, área da planta, altura de planta, número de folhas externas, massa fresca de folhas externas, massa seca de folhas externas, altura da cabeça, diâmetro da cabeça, número de folhas internas, massa fresca de folhas internas, massa seca de folhas externas, classificação do peso da cabeça, compacidade e produção por hectare. A cultivar 60 Dias apresentou maiores valores nos componentes de produção e conseqüentemente maior produtividade. A aplicação de boro influencia linearmente nos teor de boro foliar, diâmetro de cabeça e número de folha interna. As doses de boro interferem na produtividade de repolho, sendo que na cultivar 60 Dias a dose máxima é de $7,2 \mathrm{~kg} \mathrm{ha}^{-1}$ e para cultivar Chato de Quintal a dose mínima deve ser de $1,06 \mathrm{~kg} \mathrm{ha}^{-1}$.

Palavras-chave: Brassica oleracea var. capitata, micronutrientes, produção, adubação.

\section{ABSTRACT}

\section{Yield of cabbage cultivars depending on levels of boron}

The cabbage crop is cultivated in small areas and requires much labor, this crop being mostly driven by family farmers. This study aimed to evaluate the effect of boron levels in different cultivars of cabbage in western Mato Grosso do Sul state, Brazil. The experiment was carried out at the Universidade Estadual de Mato Grosso do Sul, Unidade Universitária de Aquidauana. The experimental design was randomized blocks in factorial scheme $2 \times 5$, two cultivars and five doses of boron, with four replications. We evaluated the following features: boron foliar plant area, plant height, number of outer leaves, fresh weight of outer leaves, leaf content of boron, plant area, plant height, number of outer leaves, fresh weight of outer leaves, dry weight of outer leaves, classification according to head weight, compactness and yield per hectare. The cultivar 60 Dias showed higher values for yield components and consequently greater productivity. The application of boron influences linearly in the boron content of leaves, head diameter and number of inner leaves. The boron levels interfered the yield of cabbage, the maximum dose for '60 Dias' being $7.2 \mathrm{~kg} \mathrm{ha}^{-1}$ and the minimum necessary dose for the cv. Chato de Quintal being $1.06 \mathrm{~kg} \mathrm{ha}^{-1}$.

Keywords: Brassica oleracea var. capitata, micronutrients, production, fertilization.

(Recebido para publicação em 10 de agosto de 2011; aceito em 31 de julho de 2012) (Received on August 10, 2011; accepted on July 31, 2012)

$\mathrm{O}$ repolho (Brassica oleracea var. capitata) é planta herbácea, bienal e muito consumido no Brasil, tendo grande presença na dieta alimentar das famílias. Dentre as hortaliças o repolho constitui-se em alimento de excelente qualidade, apresentando teores apreciáveis de $\beta$-caroteno, cálcio e de vitamina C (Ferreira et al., 2002). A cultura do repolho, como qualquer outra hortaliça, apresenta caráter social devido ao número de empregos gerados em consequência da exigência de mão-de-obra desde a semeadura até a comercialização. Estima-se que cada hectare plantado com hortaliças possa gerar, em média, entre 3 a 6 empregos diretos e um número idêntico de indiretos (Melo \& Vilela 2007).

No estado do Mato Grosso do Sul a produção de repolho no ano de 2010 foi de aproximadamente 1.038 toneladas sendo que esta brássica está entre as principais olerícolas comercializadas no estado com volume de 7.123 toneladas perdendo somente para o tomate, melancia, batata e cebola (Ceasa, 2012). Desta forma o abastecimento do mercado local é oriundo de outros estados da Federação estando o MS somente com uma pequena contribuição de $0,70 \%$ (Ceasa, 2012).

Originalmente o repolho é uma hortaliça de clima temperado, independe do fotoperíodo, sendo a temperatura o fator limitante para o desenvolvimento da planta (Silva Júnior, 1987; Filgueira, 2008). Contudo, ao longo do tempo, foram obtidas cultivares adaptadas a temperaturas elevadas, ampliando conseqüentemente os períodos de plantio e de colheita. Assim, pela escolha criteriosa da cultivar, a época de plantio estende-se ao longo do ano (Filgueira, 2008).

As brássicas têm grande capacidade de extração de nutrientes do solo e apresentam grande conversão em pouco tempo e, para fornecer nutrientes em quantidades adequadas e equilibradas é necessário, entre outros fatores, conhe- 
cer as exigências nutricionais de cada variedade botânica (Kimoto, 1993).

O boro tem papel importante no desenvolvimento e elongação celular e na integridade estrutural da parede celular das dicotiledôneas (Power \& Woods, 1997; Hu et al., 1997), onde também está relacionado com transporte de açúcares, lignificação, metabolismo de carboidratos, metabolismo de RNA, respiração, metabolismo de ácido indol acético, metabolismo de fenol de ascorbato (Cakmak \& Römheld, 1997).

No repolho o boro atua diretamente no crescimento e desenvolvimento, pois está relacionado aos processos metabólicos, como no crescimento e expansão celular, incorporação do cálcio na parede celular, que vem a auxiliar na biossíntese da mesma (Alvares et al., 1985) e na manutenção da integridade da membrana plasmática (Santos et al., 1990). Ainda, segundo os autores, as cabeças serão compactas com a suplementação do boro, resultando favoravelmente na qualidade final do produto (Alvares et al., 1985). Assim, o repolho é classificado como de média exigência desse micronutriente (Bergamim et al., 2005).

Culturas deficientes em boro apresentam seus pontos de crescimento afetados, diminuindo consequentemente a qualidade do produto e reduzindo a produção. A falta de boro também provoca o rápido endurecimento da parede celular, porque mesmo formando complexos com carboidratos, a disposição das micelas de celulose fica prejudicada, o que não permite o aumento normal do volume da célula (Malavolta, 1980). Lenoble et al (2000) desenvolveram a hipótese que altas concentrações de boro protegem o crescimento radicular em situações em que altos teores de alumínio normalmente seriam inibidores.

O presente trabalho teve como objetivo avaliar o efeito de doses de boro em diferentes cultivares de repolho na região oeste do estado de Mato Grosso do Sul.

\section{MATERIAL E MÉTODOS}

O experimento foi realizado na Universidade Estadual de Mato Grosso do
Sul, na área experimental da Unidade Universitária de Aquidauana (20²0'S, $55^{\circ} 48^{\prime} \mathrm{W}$, altitude 174 metros).

O clima da região, segundo a classificação de Köppen, é do tipo Aw, definido como clima tropical quente sub-úmido, com precipitação média anual de $1200 \mathrm{~mm}$, estação chuvosa no verão e seca no inverno. As temperaturas máximas podem ultrapassar os $40^{\circ} \mathrm{C}$ e ocorrem geralmente nos meses de outubro a fevereiro. $\mathrm{O}$ experimento foi conduzido nos meses de março a julho de 2010.

O solo da área experimental é classificado como Argissolo Vermelho-Amarelo Distrófico, fisicamente profundo, moderadamente drenado (Embrapa, 2006). As características químicas do solo foram determinadas antes da instalação do experimento: $\mathrm{pH}\left(\mathrm{CaCl}_{2}\right)=5,5$; $\mathrm{H}+\mathrm{Al}=21 \mathrm{mmol}_{\mathrm{c}} \mathrm{dm}^{-3} ; \mathrm{Ca}=62 \mathrm{mmol}_{\mathrm{c}}$ $\mathrm{dm}^{-3} ; \mathrm{Mg}=22 \mathrm{mmol}_{\mathrm{c}} \mathrm{dm}^{-3} ; \mathrm{P}($ resina $)=$ $68 \mathrm{mg} \mathrm{dm}^{-3} ; \mathrm{K}=7,0 \mathrm{mmol}_{\mathrm{c}} \mathrm{dm}^{-3}$; Matéria orgânica $=52 \mathrm{~g} \mathrm{dm}^{-3} ; \mathrm{CTC}^{\mathrm{c}}=112 \mathrm{mmol}_{\mathrm{c}}$ $\mathrm{dm}^{-3} ; \mathrm{V} \%=81 ; \mathrm{Cu}=8,0 \mathrm{mg} \mathrm{dm}{ }^{-3}, \mathrm{Fe}=$ $75,0 \mathrm{mg} \mathrm{dm}^{-3}, \mathrm{Mn}=20,6 \mathrm{mg} \mathrm{dm}^{-3}, \mathrm{Zn}=$ $0,9 \mathrm{mg} \mathrm{dm}^{-3}$ e $\mathrm{B}=0,32 \mathrm{mg} \mathrm{dm}^{-3}$. Para Ribeiro et al. (1999) teores de boro entre 16 a $35 \mathrm{mg} \mathrm{dm}^{-3}$ é considero baixo.

$\mathrm{O}$ delineamento experimental utilizado foi de blocos casualizados no esquema fatorial $2 \times 5$, sendo duas cultivares (Chato de Quintal e 60 Dias) cultivares essas utilizadas na região e cinco doses de boro $(0 ; 2,5 ; 5,0 ; 7,5$ e $10,0 \mathrm{~kg} \mathrm{ha}^{-1}$ ), na forma de acido bórico por apresentar maior solubilidade, com quatro repetições. As parcelas foram constituídas por quatro linhas de 1,6 $\mathrm{m}$ dispostas no espaçamento de $0,8 \mathrm{x}$ $0,4 \mathrm{~m}$, sendo cultivadas 16 plantas por parcela. A adubação básica de plantio foi realizada utilizando-se $250 \mathrm{~kg} \mathrm{ha}^{-1} \mathrm{de}$ NPK na fórmula 04-20-20 no momento do transplante das mudas, conforme análise do solo.

A semeadura foi realizada em 17 de março de 2010, utilizando bandejas de poliestireno de 128 células, preenchidas com substrato organo-mineral, marca comercial Plantmax ${ }^{\circledR}$ hortaliças, mantidas em ambiente protegido e irrigadas diariamente. Aos 30 dias após a emergência, quando as plantas apresentavam quatro a cinco folhas definitivas, foram transplantadas para o campo. As doses de boro foram aplicadas ao solo, manualmente, 15 dias após o transplante das mudas, nas entrelinhas.

O controle de plantas invasoras foi realizado por capina manual, e os demais tratos culturais e fitossanitários foram os normalmente recomendados para a cultura. $\mathrm{O}$ fornecimento de água deu-se por meio de sistema de irrigação por aspersão convencional. A adubação nitrogenada em cobertura foi realizada aplicando-se $140 \mathrm{~kg} \mathrm{ha}^{-1}$ de nitrogênio, utilizando como fonte a uréia, parcelando aos 20 e 40 dias após o transplante (Ribeiro et al., 1999).

Avaliaram-se os teores de boro foliar e os componentes de produção. Para determinação do teor de boro foliar, foram coletadas 10 folhas recém maduras no início da formação da cabeça das plantas de repolho. Em seguida, o material foi seco em estufa com circulação forçada de ar com temperatura de $65^{\circ} \mathrm{C}$, por cerca de 72 horas. Depois de seco, o material foi moído em moinho tipo Wiley equipado com peneira de malhas com abertura de $1 \mathrm{~mm}$ e acondicionado em saquinhos para análises, seguindo-se os métodos descritos por Malavolta et al. (1997).

Em se tratando das demais características, os componentes da produção, foram amostradas seis plantas da área útil de cada parcela, avaliando-se: Área da planta (largura x comprimento) e altura de planta $(\mathrm{cm})$, mensurados com régua graduada; Número de folhas externas [contagem das folhas não comerciais (folhas abertas)]; Número de folhas internas (retirada gradativa das folhas da cabeça e contagem até a última folha); Altura e diâmetro transversal da cabeça (mensurados com auxílio de uma régua em superfície plana); Compacidade conforme proposto por Muniz (1988), que classifica como $1=$ fofa; 2 = compacidade média; $3=$ firme, e produtividade por hectare; A classificação do peso da cabeça foi realizada conforme proposto por Vidigal et al. (2007), onde $0=<250 \mathrm{~g} ; 1=250-500 \mathrm{~g}$; $2=500-750 \mathrm{~g} ; 3=750-1.000 \mathrm{~g} ; 4=1.000-$ $1.500 \mathrm{~g} ; 5=1.500-2.000 \mathrm{~g}$ e $6=>2.000$ $\mathrm{g}$; Massa fresca e seca de folhas externas e internas: realizada através da pesagem da massa fresca das folhas e depois secagem em estufa de circulação de ar 
forçada com temperatura de $65^{\circ} \mathrm{C}$, por cerca de 72 horas, em seguida pesagem para determinar a massa seca.

A colheita foi realizada semanalmente, à medida que as cabeças de repolho atingiam o ponto de colheita, sendo que a cultivar 60 Dias e a Chato de Quintal tiveram início aos 90 e 120 dias após a semeadura, respectivamente.

Os dados foram submetidos à análise de variância (teste F), e as médias das cultivares foram comparadas pelo teste de Tukey a $5 \%$ de probabilidade. As doses de $\mathrm{B}$ foram submetidas à análise de regressão. As análises estatísticas foram processadas utilizando-se o programa de análise estatística Sanest.

\section{RESULTADOS E DISCUSSÃO}

Constatou-se que houve efeito significativo para as cultivares, doses e interação entre cultivares e doses de boro na cultura do repolho.

Houve efeito significativo para a cultivar Chato de Quintal em relação à cultivar 60 Dias, em relação à área da planta, altura de planta e diâmetro de cabeça (Tabela 1).

A cultivar 60 Dias foi superior quando se avaliou a altura da cabeças e a compacidade (Tabela 1). Carneiro et al. (1995), trabalhando com doses de boro, com e sem matéria orgânica, observaram uma regressão quadrática da altura da cabeça do repolho, constatando que níveis elevados de boro provocam
Tabela 1. Valores médios do teor de boro foliar (TBF), área da planta (ARP), altura de planta (ALP), altura da cabeça (AC), diâmetro da cabeça (DC) e compacidade (COMP) em função das cultivares e doses de boro na cultura do repolho (mean values of leaf boron content (TBF), area of the plant (ARP), plant height (ALP), head height (AC), head diameter (AD) and compactness (COMP) depending on the cultivars and doses of boron in the cabbage crop). Aquidauana, UEMS, 2010.

\begin{tabular}{lcccccc}
\hline Tratamentos & $\begin{array}{c}\text { TBF } \\
(\mathbf{m g} / \mathbf{k g})\end{array}$ & $\begin{array}{c}\text { ARP } \\
\left(\mathbf{( m}^{\mathbf{2}}\right)\end{array}$ & $\begin{array}{c}\text { ALP } \\
\mathbf{( c m )}\end{array}$ & $\begin{array}{c}\text { AC } \\
\mathbf{( c m )}\end{array}$ & $\begin{array}{c}\text { DC } \\
(\mathbf{c m})\end{array}$ & COMP \\
\hline Cultivares & & & & & & \\
\hline Chato de Quintal & $129,60 \mathrm{a}$ & $0,52 \mathrm{a}$ & $41,70 \mathrm{a}$ & $12,67 \mathrm{~b}$ & $14,77 \mathrm{a}$ & $1,73 \mathrm{~b}$ \\
60 Dias & $117,00 \mathrm{a}$ & $0,33 \mathrm{~b}$ & $34,96 \mathrm{~b}$ & $13,85 \mathrm{a}$ & $13,31 \mathrm{~b}$ & $2,20 \mathrm{a}$ \\
\hline Doses de B (kg ha $\left.\mathbf{~ h}^{-1}\right)$ & & & & & & \\
\hline 0 & 41,50 & 0,44 & 38,19 & 12,76 & 12,41 & 2,00 \\
2,5 & 67,00 & 0,42 & 35,36 & 13,28 & 13,72 & 2,16 \\
5,0 & 142,50 & 0,46 & 38,97 & 13,16 & 14,08 & 2,16 \\
7,5 & 176,00 & 0,40 & 39,53 & 14,01 & 14,48 & 1,83 \\
10 & 189,50 & 0,41 & 39,58 & 13,07 & 15,50 & 1,67 \\
\hline CV $(\%)$ & 18,81 & 12,49 & 9,57 & 8,85 & 7,68 & 22,94 \\
\hline
\end{tabular}

Médias seguidas pela mesma letra na coluna, não diferem entre si pelo teste de Tukey a $5 \%$ de probabilidade (means followed by same letter in column do not differ by Tukey test at $5 \%$ probability).

redução da altura.

Moraes et al. (2007) obtiveram valores maiores da testemunha aos encontrados neste trabalho, trabalhando com consorcio de repolho 'Chato de Quintal' e 'Capuchinha', com e sem aplicação de cama de frango, onde o diâmetro da cabeça chegou a $16,72 \mathrm{~cm}$, na cidade de Dourados (MS).

Quando se avaliou as doses de boro observou-se efeito significativo para o teor de boro foliar e diâmetro de cabeça (Figura 1). Os teores médios de boro foliar se ajustaram à regressão linear
(Figura 1a), sendo esses valores maiores aos relatados por Trani et al. (1996), que afirmam que o nível adequado do teor de boro foliar do repolho, para um desenvolvimento adequado, está situado na Stevenson (1991), o boro juntamente com a matéria orgânica do solo, formam complexos, que ao serem mineralizados pelos microorganismos, liberam o boro em formas disponíveis para as plantas.

Pizetta et al. (2005), trabalhando com as doses, 0, 2, 4 e $8 \mathrm{~kg} \mathrm{ha}^{-1}$ de boro faixa de $25-75 \mathrm{mg} \mathrm{kg}^{-1}$. De acordo com

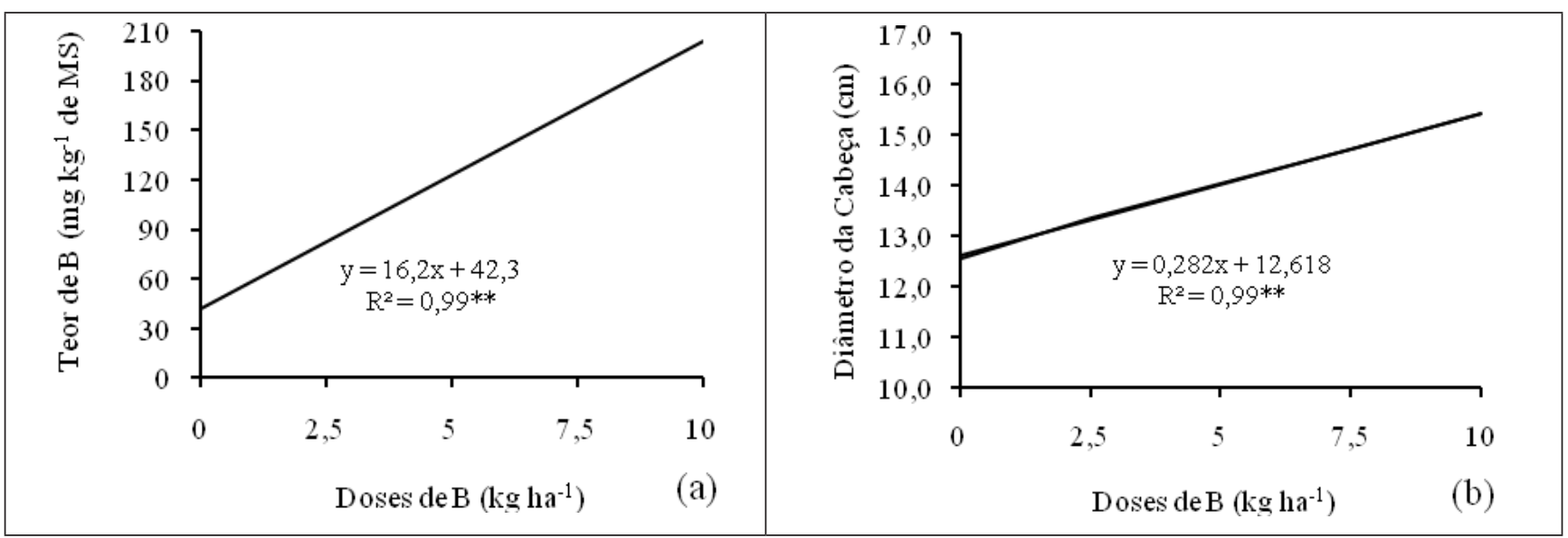

Figura 1. Teor de boro foliar (a) e diâmetro da cabeça (b) em função de doses de boro na cultura do repolho (boron content of leaf (a) and head diameter (b) depending on boron levels in the cabbage crop). ** significância a 1\% de probabilidade (significant at $1 \%$ ). Aquidauana, UEMS, 2010. 
Tabela 2. Valores médios do número de folhas externas (FE), matéria fresca de folhas externas (MFE), matéria seca de folhas externas (MSE), número de folhas internas (FI), matéria seca de folhas internas (MSI) em função das cultivares e doses de boro na cultura do repolho (mean values for the number of outer leaves (FE), fresh matter of outer leaves (MFE), dry matter of outer leaves (MSE), number of inner leaves (FI), dry matter of inner leaves (MSI) according to the cultivars and doses of boron in the cabbage crop). Aquidauana, UEMS, 2010.

Tratamentos $\quad$ FE $\quad \begin{gathered}\text { MFE (g/ } \\ \text { planta) }\end{gathered} \underset{\begin{array}{c}\text { MSE } \\ \text { (g/planta) }\end{array}}{\text { FI }} \quad \begin{gathered}\text { MSI } \\ \text { (g/planta) }\end{gathered}$

\begin{tabular}{lccccc}
\hline Cultivares & \multicolumn{5}{l}{} \\
\hline Chato de Quintal & $14,72 \mathrm{a}$ & $0,860 \mathrm{a}$ & $0,126 \mathrm{a}$ & $40,80 \mathrm{a}$ & $0,061 \mathrm{~b}$ \\
60 Dias & $13,60 \mathrm{a}$ & $0,494 \mathrm{~b}$ & $0,083 \mathrm{~b}$ & $41,09 \mathrm{a}$ & $0,045 \mathrm{a}$ \\
\hline Doses de B (kg/ha) & & & & & \\
\hline 0 & 13,36 & 0,668 & 0,099 & 36,45 & 0,049 \\
2,5 & 13,14 & 0,657 & 0,103 & 41,18 & 0,050 \\
5,0 & 16,05 & 0,713 & 0,094 & 41,01 & 0,052 \\
7,5 & 12,94 & 0,663 & 0,103 & 40,33 & 0,055 \\
10 & 15,30 & 0,684 & 0,121 & 45,74 & 0,057 \\
\hline CV (\%) & 23,19 & 17,95 & 22,72 & 9,42 & 15,83 \\
\hline
\end{tabular}

Médias seguidas pela mesma letra, na coluna, não diferem entre si pelo teste de Tukey a $5 \%$ de probabilidade (means followed by same letter in column do not differ by Tukey test at $5 \%$ probability).

em repolho em solo arenoso, também observaram uma regressão linear crescente nos teores de boro foliar, variando entre 33 e $81 \mathrm{mg} \mathrm{kg}^{-1}$ na folha em função das doses.

Para o efeito das doses de boro em relação ao diâmetro da cabeça observa-se ajuste dos dados a uma regressão linear crescente, conforme ilustrado (Figura 1b). Pizetta et al. (2005) verificaram aumento linear crescente do diâmetro da cabeça de acordo com as doses de boro, resultado semelhantes ao obtido neste trabalho.

A cultivar Chato de Quintal apresentou valores superiores na matéria fresca de folhas externas e matéria seca de folhas externas enquanto que a cultivar 60 Dias apresentou valor superior de matéria seca de folhas internas (Tabela 2). Santos \& Ferreira (1991), trabalhando com as cultivares União de Verão, 60 Dias, Coração de Boi, Chato de Quintal e Chato de Brunswick, observaram que a cultivar 60 Dias apresentou melhor desempenho entres as cultivares avaliadas.

No entanto, não foi observado efeito significativo para o número de folhas externas e número de folhas internas entre as cultivares (Tabela 2). Alves et al. (2006), trabalhando com absorção ficação utilizada por Pizetta et al. (2005) que, trabalhando com aplicação de boro na cultura do repolho, verificaram que a adição de 6 e $8 \mathrm{~kg} \mathrm{ha}^{-1}$ de boro diminuiu o número de cabeças na classe $1,2,3$ e $4(<1,5 \mathrm{~kg})$ e aumentou na classe 5 e 6 (1,5-2,5 kg), atingindo $97 \%$ de cabeças nesta última classe. Já Bergamin (2003) verificou que a aplicação de $8 \mathrm{~kg} \mathrm{ha}^{-1}$ de boro, obteve uma redução de $60 \%$ de cabeças de repolho na classe 5 , e ocorreu aumento de $181 \%$ na classe 6 em relação à ausência da aplicação de boro.

Quando se determinou a produtividade (Figura 2d), os dados se ajustaram a uma regressão quadrática para cultivar 60 Dias com ponto de máxima de 7,2 kg $\mathrm{ha}^{-1}$ de boro. Já para a cultivar Chato de Quintal, os valores se ajustaram a uma regressão quadrática com ponto de mínima de 1,06 kg ha ${ }^{-1}$ de boro. Estes resultados divergem do encontrado por Bergamim et al. (2005a). Estes autores verificaram que a produção de repolho se ajustou a uma regressão linear em função da aplicação de doses de boro. Carneiro et al. (1995), aplicando doses de boro na ausência de matéria orgânica, obtiveram uma produção superior à encontrada neste trabalho, alcançando $38,78 \mathrm{tha}^{-1}$, e as doses se ajustaram a uma regressão quadrática para a produção de repolho, com ponto de máxima de $20 \mathrm{~kg} \mathrm{ha}^{-1}$ de bórax.

No entanto, Coutinho et al. (1999) verificaram que a máxima produção foi obtida com $4 \mathrm{~kg} \mathrm{ha}^{-1}$ de boro e que quando foram aplicados $12 \mathrm{~kg} \mathrm{ha}^{-1}$ houve redução de produção, o que já havia sido relatado por Dixit \& Singh (1997).

A cultivar 60 Dias apresentou maiores valores nos componentes de produção e, conseqüentemente, maior produtividade. A aplicação de boro influencia linearmente o número de folhas que compõem a cabeça do repolho, independente da cultivar. As doses de boro interferem na produtividade de repolho, sendo que para a cultivar 60 Dias a dose máxima é de $7,2 \mathrm{~kg} \mathrm{ha}^{-1}$ enquanto que, para a cultivar Chato de Quintal, a dose mínima deve ser de $1,06 \mathrm{~kg} \mathrm{ha}^{-1}$.

Há na literatura poucos estudos enfocando a adubação boratada na cultura do repolho. Vale ressaltar que a produtividade da cultura é dependente do solo, condições climáticas, cultivar, 


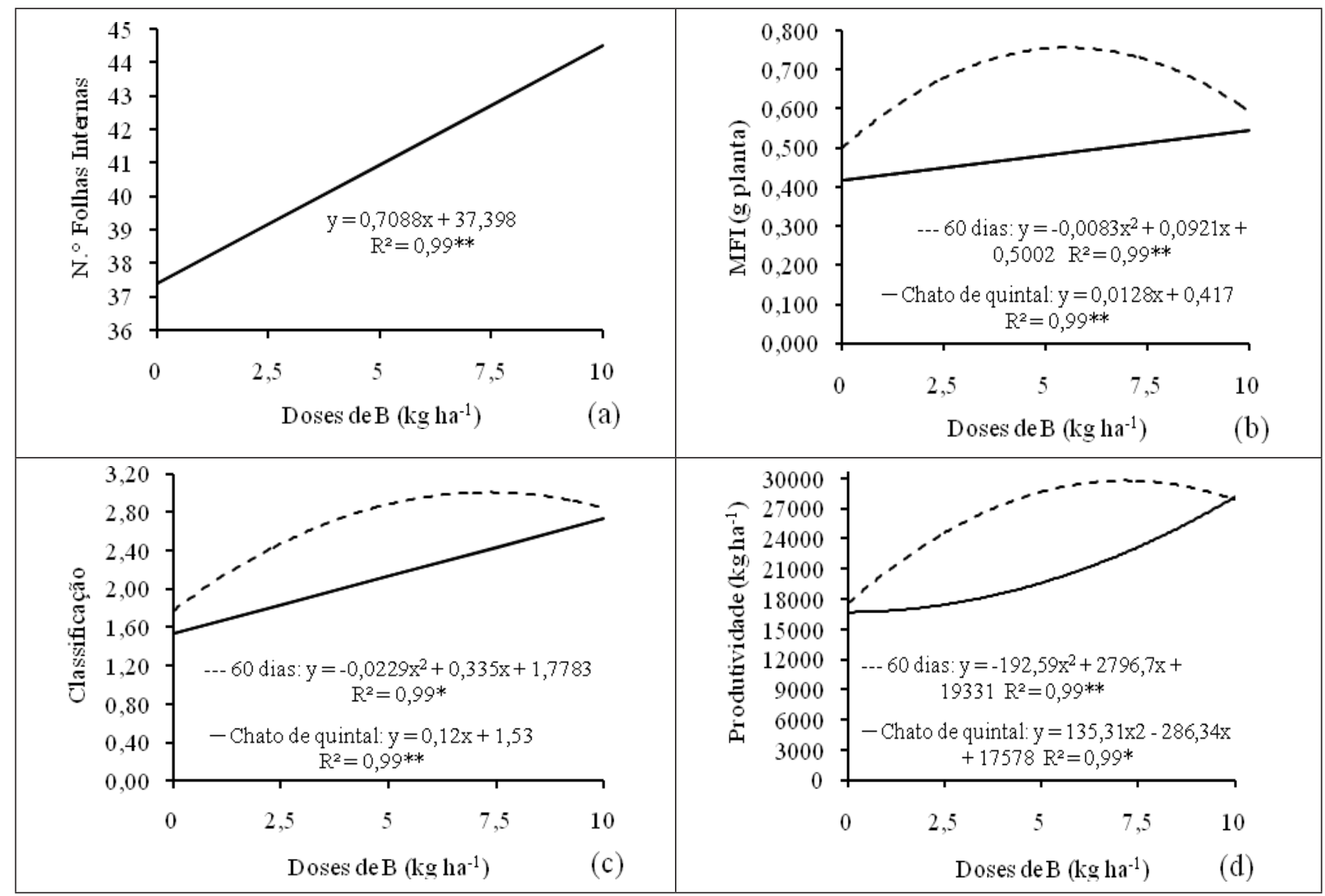

Figura 2. Número de folhas internas em função das doses de boro (a), matéria fresca de folhas internas (b), classificação do peso da cabeça (c) e produtividade (d) em função de doses de boro na cultura do repolho (number of internal leaves depending on doses of boron (a) fresh matter of young leaves (b) classification of the weight of the head (c) and yield (d) depending on doses of boron in the cabbage crop). * significância a 5\% (significant at 5\%) e ** significância a 1\% de probabilidade (significant at 1\%). Aquidauana, UEMS, 2010.

manejo do solo, manejo da cultura e, principalmente, da adubação. Desta forma, a manutenção correta e adequada da cultura é de fundamental importância para alcançar boa produtividade resultando em retorno econômico.

\section{REFERÊNCIAS}

ALVARES MC; OLIVEIRA SA; MATTOS JKA.; MESQUITA FILHO MV. 1985. Resposta de repolho à adubação com bórax. Horticultura Brasileira 3: 18-21.

ALVES AU; PRADO RM; GONDIM ARO; CECÍLIO FILHO AB; SOUZA FV. 2006. Influencia do boro sobre o desenvolvimento do repolho. In: CONGRESSO BRASILEIRO DE OLEIRICULTURA, 44. Anais... Jaboticabal: $\mathrm{ABH}$.

BERGAMIN LG. 2003. Resposta de repolho à aplicação de boro associada à utilização de adubo orgânico. Jaboticabal: UNESP-FCAV. 38p (Dissertação mestrado).

BERGAMIN LG; CRUZ MCP; FERREIRA ME; BARBOSA JC. 2005. Produção de repolho em função da aplicação de boro associada a adubo orgânico. Horticultura Brasileira 23:311-315.
CAKMAK I; RÖMHELD V. 1997. Boron deficiency-induced impairments of celular functions in plants. Plant and Soil 193: 71-83.

CARNEIRO IF; ALMEIDA NETO JX; NAVES RV; CHAVES LJ. 1995. Efeitos de diferentes níveis de boro, na presença e ausência de matéria orgânica, na cultura do repolho. Escola de Agronomia e Veterinária 25: 1-11.

CEASA-MS. 2012. Centrais de Abastecimento do Mato Grosso do Sul. Dados de volume e peso. Disponível em: <http://www.ceasa.ms.gov. br/>. Acesso em: 15 mar. 2012.

COUTINHO ELM; NATALE W; NISHIKAWA MAN; CASTELLANE PD. 1999. Efeitos da calagem e da adubação com boro na produção e no estado nutricional das plantas de repolho. In: CONGRESSO BRASILEIRO DE CIÊNCIA DO SOLO, 27. Anais... Brasília: SBCS (CD-ROM).

DIXIT HC; SINGH V. 1997. Effect of boron and calcium on yield and nutrition of cabbage (Brassica oleracea convar capitata var capitata) in Ustipsamment. Indian Journal of Agricultural Sciences 67: 87-88.

EMBRAPA. EMPRESA BRASILEIRA DE PESQUISAAGROPECUÁRIA. 2006. Centro Nacional de Pesquisa de Solos. Sistema brasileiro de classificação de solos. Rio de Janeiro: Embrapa. 306p.
FERREIRA WR; RANAL MA; FILGUEIRA FAR. 2002. Fertilizantes e espaçamento entre plantas na produtividade da couve da malásia. Horticultura Brasileira 20: 635-640.

FILGUEIRAFAR. 2008. Agrotecnologia moderna na produção e comercialização de hortaliças. Novo manual de olericultura. 3. Ed. Viçosa: UFV. 421p.

HU H; PENN SG; LEBRILLA CB; BROWN PH. 1997. Isolation and characterization of soluble boron complexes in higher plants: the mechanism of phloem mobility of boron. Plant Physiology 113: 649-655.

KIMOTO T. 1993. Nutrição e adubação de repolho, couve-flor e brócolo. In: FERREIRA ME; CASTELLANE PD; CRUZ MPC. Nutrição e adubação de hortaliças. Piracicaba: POTAFOS. 480p.

LENOBLE ME; BLEVINS DG; MILLES RJ. 2000. Boro extra mantém crescimento radicular sob condições de alumino tóxico. Informações agronômicas 92: 3-4.

MALAVOLTA E. 1980. Elementos de Nutrição Mineral de Plantas. São Paulo: Agronômica Ceres. 251p.

MALAVOLTA E; VITTI CG; OLIVEIRA SA. 1997. Avaliação do estudo nutricional das plantas: princípios e aplicações. Piracicaba: Potafós. 319p. 
MELO PCT; VILELA NJ. 2007. Importância da cadeia produtiva brasileira de hortaliças. Reunião Ordinária da Câmara Setorial da Cadeia 13. Produtiva de Hortaliças/ MAPA. Brasília. 11p. Disponível em: <www. abhorticultura.com.br/downloads/cadeia produtiva.pdf $>$. Acesso em: 28 jun. 2012.

MORAES AA; VIEIRA MC; ZÁRATE NAH. 2007. Produção de repolho "Chato de Quintal" e da capuchinha "Jewel”, solteiros e consorciados, sem e com cama de frango semidecomposta incorporada ao solo. Ciência e Agrotecnologia 31: 731-738.

MUNIZ JOL. 1988. Avaliação de cultivares e híbridos de repolho. Horticultura Brasileira 6: 14-15.

PIZETTA LC; FERREIRA ME; CRUZ MCP; BARBOSA JC. 2005. Resposta de brócolis, couve-flor e repolho à adubação com boro em solo arenoso. Horticultura Brasileira
23: 51-56.

POWER PP; WOODS WG. 1997. The chemistry of boron and its speciation in plants. Plant and Soil 193: 1-14.

RIBEIRO AC; GUIMARÃES PTG; ALVAREZ VH. 1999. Recomendações para o uso de corretivos efertilizantes em Minas Gerais - $5^{a}$ aproximação. Viçosa: UFV. 359p.

SANTOS AJ; FERREIRA PV. 1991. Comportamento de cultivares de repolho (Brassica oleracea var. capitata L.) introduzidas no município de Maceió Alagoas. Ciência Agrícola 1: 21-28.

SANTOS IS; BARBEADO CJ; PIPITAI, R; FERREIRA SM; NAKAGAWA J. 1990. Estudo da relação $\mathrm{Ca} \times \mathrm{B}$ na cultura do pimentão. Horticultura Brasileira 8: 19-23.

SILVA JÚNIOR AA. 1987. Repolho: fitologia, fitotecnia, tecnologia alimentar e mercadológica. Florianópolis: EMOASC. $259 \mathrm{p}$.

STEVENSON FJ. 1991. Organic mattermicronutrient reactions in soil. In: MORTVEDT JJ; COX FR; SHUMAN LM; WELCH RM. (ed) Micronutrients in agriculture. 2. ed. Madison: Soil Science Society of America. p.145-186.

TRANI PE; PASSOS FA; AZEVEDO JA; TAVARES M. 1996. Brócolos, couve-flor e repolho. In: RAIJ BVAN; CANTARELLA H; QUAGGIO JA.; FURLANI AMC. (ed) Recomendações de adubação e calagem para o Estado de São Paulo. Campinas: Instituto Agronômico/Fundação IAC. p.175.

VIDIGAL SM; PEREIRA PRG; PEDROSA MW. 2007. Repolho. In: PAULA JÚNIOR TJ; VENZON M. (coord). 101 Culturas: manual de tecnologias agrícolas. Belo Horizonte: EPAMIG. p.655-674. 